\title{
A Research of Entrepreneurial Environment Evaluation of Shenzhen Based on GEM
}

\author{
Hui Xu (Corresponding author) \\ Department of Economics and Management, Harbin Institute of Technology \\ Shenzhen Graduate School, Shenzhen 518055, China \\ Tel: 86-755-2603-3494Ｅ-mail: xuhui5859@126.com
}

\section{Abstract}

The paper investigates the current status of entrepreneurial environment in Shenzhen based on Global Entrepreneurship Monitor (GEM) model. Through expert interviews, I analyze nine aspects of entrepreneurial environment of Shenzhen and compare them with other GEM data. These aspects include financial support, government policies, government programs, education and training, research and development transfer, commercial and professional infrastructure, access to physical infrastructure, market openness and cultural and social norms.

Keywords: Entrepreneurial Environment, GEM, Evaluation, Shenzhen

\section{Introduction}

Entrepreneurial activities are accelerating economic development of Shenzhen. The paper uses Global Entrepreneurship Monitor (GEM) model to evaluate the current status of entrepreneurial environment in Shenzhen. The Global Entrepreneurship Monitor (GEM) research was started by London Business School and Babson College and has been expanded to 56 countries. This paper selected 30 experts to fill out the expert questionnaire. These experts are from government, enterprises, financial institutions and educational institutions. The expert questionnaire covers nine aspects of environmental conditions including financial support, government policies, government programs, education and training, research and development transfer, commercial and professional infrastructure, market openness, access to physical infrastructure and cultural and social norms. Each question of the questionnaire is an affirmative proposition and experts give 1-5 different scores according to their recognition on each issue. The higher the degree of certainty the option will score higher, indicating the better entrepreneurial environment. The GEM indicators are calculated by simple arithmetic average. If the score is higher than 3 , the evaluation is positive and the evaluation is negative when the score is less than 3. Then Shenzhen GEM indicators are compared one by one with the indicators of Shanghai, the average of main China cities (China), the average of global countries (Global). The data of Shanghai, China and Global used in this paper are from Yang Ye \& Yu Yan. (2007).

\section{Investigation result and comparison}

\subsection{Financial support}

Financial support measures the availability of new and growing businesses accessing to financial resources. Financial support includes supports of government funding, venture capital fund and other social investment and financing resources. The result is showed in Figure 1(The indicators meaning showed in Table 1).

\subsection{Government policies}

Government policies encourage entrepreneurs to start businesses. The policies commonly include supportive policies about entrepreneurial activities, employment requirements, organizational requirements and tax provisions. The result is showed in Figure 2(The indicators meaning showed in Table 2)

\subsection{Government programs}

Government programs are programs which government charge to support entrepreneurial enterpriseses. They include government services and assistances to enterprises. The result is showed in Figure 3(The indicators meaning showed in Table 3). 2.4 Education and training

Education and training activities contribute to entrepreneurial activities and help turning potential business opportunities to reality. The result is showed in Figure 4(The indicators meaning showed in Table 4).

\subsection{Research and development transfer}

The process of research and development transfer means whether the result of scientific research can turn to commodity, whether the entrepreneurship is efficient, whether entrepreneurs can seize business opportunities. The result is showed in Figure 5(The indicators meaning showed in Table 5).

\subsection{Commercial and professional infrastructure}

Commercial and professional infrastructure provide professional assistance and commercial services to start-ups. The result is showed in Figure 6(The indicators meaning showed in Table 6).

\subsection{Access to physical infrastructure}

Physical infrastructure furnishes essential physical establishment to entrepreneurial activities. The accessing cost 
affect directly the efficiency of entrepreneurial enterprises. The result is showed in Figure 7(The indicators meaning showed in Table 7).

\subsection{Market openness}

Market openness means whether entry barriers exist while start-ups enter the market and whether established companies set unfair barriers to impede the entry of new enterprises. The result is showed in Figure 8(The indicators meaning showed in Table 8).

\subsection{Cultural and social norms}

Cultural and social norms measure the extent existed social and cultural norms encourage individual entrepreneurial behavior. General attitudes of people for entrepreneurship and influence of social norms on entrepreneurial behavior are investigated. The result is showed in Figure 9(The indicators meaning showed in Table 9).

\section{Conclusion}

From the investigation results and comparison, the average scores of each aspect can be calculated. For financial support, the average scores are separately 3.60, 3.26, 2.71 and 2.68(Shenzhen, Shanghai, China, Global). For government policies, they are separately $3.26,2.79,2.57$ and 2.53 . For government programs, they are separately $3.28,3.17,2.69$ and 2.65 . For education and training, they are separately $3.11,2.88,2.79$ and 2.43 . For research and development transfer, they are separately $3.32,2.81,2.44$ and 2.44. For commercial and professional infrastructure, they are separately $3.58,2.87,3.39$ and 3.23. For access to physical infrastructure, they are separately $3.92,3.06,4.16$ and 3.93. For market openness, they are separately $3.43,3.42,2.85$ and 2.79 . For cultural and social norms, they are separately $4.14,3.03,3.18$ and 2.78 .

As a whole, the entrepreneurial environment of Shenzhen is relatively good for entrepreneurial enterprises. In most of the aspects, Shenzhen is better than Shanghai, China and Global. The only aspect is access to physical infrastructure in which Shenzhen is worse than China and Global. From in-depth analysis of the composing elements, the reason for the deficiency of that aspect is that operating cost of big cities in China is too high.

Although most of the aspects are relatively good, there are some composing elements worse than Shanghai. Shenzhen government should improve these elements to optimize Shenzhen entrepreneurial environment.

\section{References}

Gao Jian. (2007). China City Entrepreneurship Monitor Report. Beijing: Qinghua University Press

Jiang Yanfu, Gao Jian, Cheng Yuan \& Qiu Qiong. (2004). Global Entrepreneurship Monitor China \& Globe 2003. Beijing: Qinghua University Press

Niels Bosma \& Jonathan Levie. (2010). Global Entrepreneurship Monitor 2009 Executive Report. [Online]. http://www.gemconsortium.org/download/1275462355373/GEM\%202009\%20Global\%20 20Rev\%20140410.pdf

Thomas Walter, Peter Rosa, Stefanie Barabas, Waswa Balunywa, Arthur Sserwanga, Rebecca Namatovu \& Sarah Kyejjusa. (2004). Global Entrepreneurship Monitor UGANDA 2004 EXECUTIVE REPORT. [Online]. http://mubs.mak.ac.ug/home/docs/GEM\%20Uganda\%202004\%20Executive\% 20Report.pdf, 26-32

Yang Ye \& Yu Yan. (2007). Analysis of Shanghai Entrepreneurial Environment and Suggestions Based on GEM Model. Journal of Shanghai University of Finance and Economics. 2007, 9(2), 82-89

Zoltan J. Acs, Pia Arenius, Michael Hay \& Maria Minniti. (2004). Global Entrepreneurship Monitor 2004 Executive Report. [Online]. http://www.gemconsortium.org/download/1275462044045/GEM_ 2004_ Exec_Report.pdf.

Table 1. Questionnaire indicators about financial support (Thomas Walter et al, 2004, pp26-32)

\begin{tabular}{|l|l|}
\hline Code & Indicator \\
\hline A01 & There is sufficient equity funding available for new and growing firms. \\
\hline A02 & There is sufficient debt funding available for new and growing firms. \\
\hline A03 & There are sufficient government subsidies available for new and growing firms. \\
\hline A04 & $\begin{array}{l}\text { There is sufficient funding available from private individuals (other than founders) for new and } \\
\text { growing firms. }\end{array}$ \\
\hline A05 & There is sufficient venture capitalist funding available for new and growing firms. \\
\hline A06 & There is sufficient funding available through initial public offerings for new and growing firms. \\
\hline
\end{tabular}


Table 2. Questionnaire indicators about government policies(Thomas Walter et al, 2004, pp26-32)

\begin{tabular}{|l|l|}
\hline Code & Indicator \\
\hline B01 & Government policies consistently favor new firms. \\
\hline B02 & The support for new and growing firms is a high priority for national policy. \\
\hline B03 & The support for new and growing firms is a high priority for local policy. \\
\hline B04 & New firms can get most of the required permits and licenses in about a week. \\
\hline B05 & The amount of taxes is NOT a burden for new and growing firms. \\
\hline B06 & $\begin{array}{l}\text { Taxes and other government regulations are applied to new and growing firms in a predictable } \\
\text { and consistent way. }\end{array}$ \\
\hline B07 & Government policies aimed at supporting new and growing firms are effective. \\
\hline
\end{tabular}

Table 3. Questionnaire indicators about government programs(Thomas Walter et al, 2004, pp26-32)

\begin{tabular}{|l|l|}
\hline Code & Indicator \\
\hline C01 & $\begin{array}{l}\text { A wide range of government assistance for new and growing firms can be obtained through } \\
\text { contact with a single agency. }\end{array}$ \\
\hline C02 & Science parks and business incubators provide effective support for new and growing firms. \\
\hline C03 & $\begin{array}{l}\text { There are an adequate number of government programs for new and growing businesses. } \\
\text { C04 }\end{array}$ \\
$\begin{array}{l}\text { The people working for government agencies are competent and effective in supporting new } \\
\text { and growing firms. }\end{array}$ \\
\hline C05 & $\begin{array}{l}\text { Almost anyone who needs help from a government program for a new or growing business can } \\
\text { find what they need. }\end{array}$ \\
\hline C06 & Government programs aimed at supporting new and growing firms are effective. \\
\hline
\end{tabular}

Table 4. Questionnaire indicators about education and training(Thomas Walter et al, 2004, pp26-32)

\begin{tabular}{|l|l|}
\hline Code & Indicator \\
\hline D01 & $\begin{array}{l}\text { Teaching in primary and secondary education encourages creativity, self-sufficiency, and } \\
\text { personal initiative. }\end{array}$ \\
\hline D02 & $\begin{array}{l}\text { Teaching in primary and secondary education provides adequate instruction in market economic } \\
\text { principles. }\end{array}$ \\
\hline D03 & $\begin{array}{l}\text { Teaching in primary and secondary education provides adequate instruction in market economic } \\
\text { principles. }\end{array}$ \\
\hline D04 & Colleges and universities have enough courses and programs on entrepreneurship. \\
\hline D05 & The level of business and management education is truly world-class. \\
\hline D06 & $\begin{array}{l}\text { The vocational, professional, and continuing education systems provide good preparation for } \\
\text { self-employment. }\end{array}$ \\
\hline
\end{tabular}

Table 5. Questionnaire indicators about research and development transfer(Thomas Walter et al, 2004, pp26-32)

\begin{tabular}{|l|l|}
\hline Code & Indicator \\
\hline E01 & $\begin{array}{l}\text { New technology, science, and other knowledge are efficiently transferred from universities and } \\
\text { public research centers to new and growing firms. }\end{array}$ \\
\hline E02 & $\begin{array}{l}\text { New and growing firms have just as much access to new research and technology as large, } \\
\text { established firms. }\end{array}$ \\
\hline E03 & New and growing firms can afford the latest technology. \\
\hline E04 & There are adequate government subsidies for new and growing firms to acquire new technology. \\
\hline E05 & $\begin{array}{l}\text { The science and technology base efficiently supports the creation of world-class new } \\
\text { technology-based ventures in at least one area. }\end{array}$ \\
\hline E06 & $\begin{array}{l}\text { There is good support available for engineers and scientists to have their ideas commercialized } \\
\text { through new and growing firms. }\end{array}$ \\
\hline
\end{tabular}


Table 6. Questionnaire indicators about commercial and professional infrastructure(Thomas Walter et al, 2004, pp26-32)

\begin{tabular}{|l|l|}
\hline Code & Indicator \\
\hline F01 & There are enough subcontractors, suppliers, and consultants to support new and growing firms. \\
\hline F02 & New and growing firms can afford the cost of using subcontractors, suppliers, and consultants. \\
\hline F03 & It is easy for new and growing firms to get good subcontractors, suppliers, and consultants. \\
\hline F04 & It is easy for new and growing firms to get good, professional legal and accounting services. \\
\hline F05 & $\begin{array}{l}\text { It is easy for new and growing firms to get good banking services (checking accounts, foreign } \\
\text { exchange transactions, letters of credit, and the like). }\end{array}$ \\
\hline
\end{tabular}

Table 7. Questionnaire indicators about access to physical infrastructure (Thomas Walter et al, 2004, pp26-32)

\begin{tabular}{|l|l|}
\hline Code & Indicator \\
\hline G01 & $\begin{array}{l}\text { The physical infrastructure (i.e. roads, utilities, communications and waste disposal) provides } \\
\text { good support for new and growing firms. }\end{array}$ \\
\hline G02 & $\begin{array}{l}\text { It is not too expensive for a new and growing firm to get good access to communications } \\
\text { (phone, Internet, etc). }\end{array}$ \\
\hline G03 & $\begin{array}{l}\text { A new and growing firm can get good access to communications (telephone, internet, etc) in } \\
\text { about a week. }\end{array}$ \\
\hline G04 & $\begin{array}{l}\text { New and growing firms can afford the cost of basic utilities (i.e. gas, water, electricity, and } \\
\text { sewer). }\end{array}$ \\
\hline G05 & $\begin{array}{l}\text { New and growing firms can get good access to utilities (i.e. gas, water, electricity and sewer) in } \\
\text { about a month. }\end{array}$ \\
\hline
\end{tabular}

Table 8. Questionnaire indicators about market openness(Thomas Walter et al, 2004, pp26-32)

\begin{tabular}{|l|l|}
\hline Code & Indicator \\
\hline H01 & The markets for consumer goods and services change dramatically from year to year. \\
\hline H02 & The markets for business-to-business goods and services change dramatically from year to year. \\
\hline H03 & New and growing firms can easily enter new markets. \\
\hline H04 & New and growing firms can afford the cost of market entry. \\
\hline H05 & New and growing firms can enter markets without being unfairly blocked by established firms. \\
\hline H06 & The anti-trust legislation is effective and well enforced. \\
\hline
\end{tabular}

Table 9. Questionnaire indicators about cultural and social norms(Thomas Walter et al, 2004, pp26-32)

\begin{tabular}{|l|l|}
\hline Code & Indicator \\
\hline I01 & $\begin{array}{l}\text { The national culture is highly supportive of individual success achieved through own personal } \\
\text { efforts. }\end{array}$ \\
\hline I02 & The national culture emphasizes self-sufficiency, autonomy, and personal initiative. \\
\hline I03 & The national culture encourages entrepreneurial risk-taking. \\
\hline I04 & The national culture encourages creativity and innovativeness. \\
\hline I05 & $\begin{array}{l}\text { The national culture emphasizes the responsibility that the individual (rather than the collective) } \\
\text { has in managing his or her own life. }\end{array}$ \\
\hline
\end{tabular}

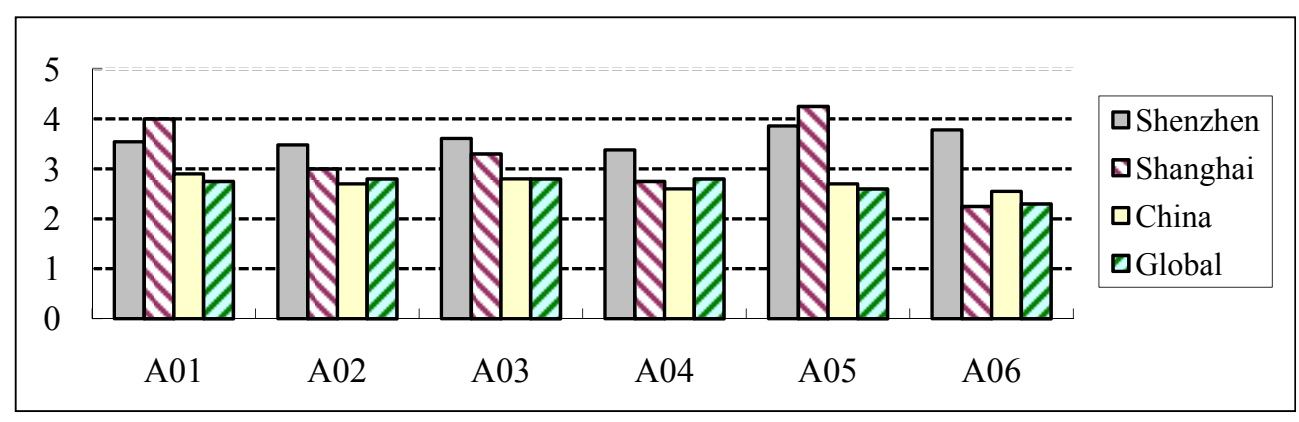

Figure 1. The Result Comparison of Expert Questionnaire (Financial Support) 


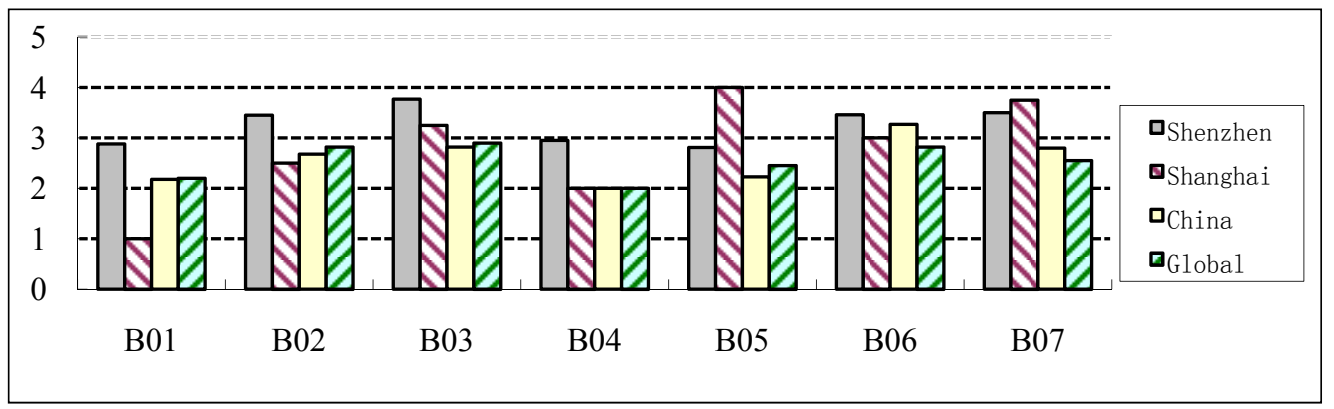

Figure 2. The Result Comparison of Expert Questionnaire (Government Policies)

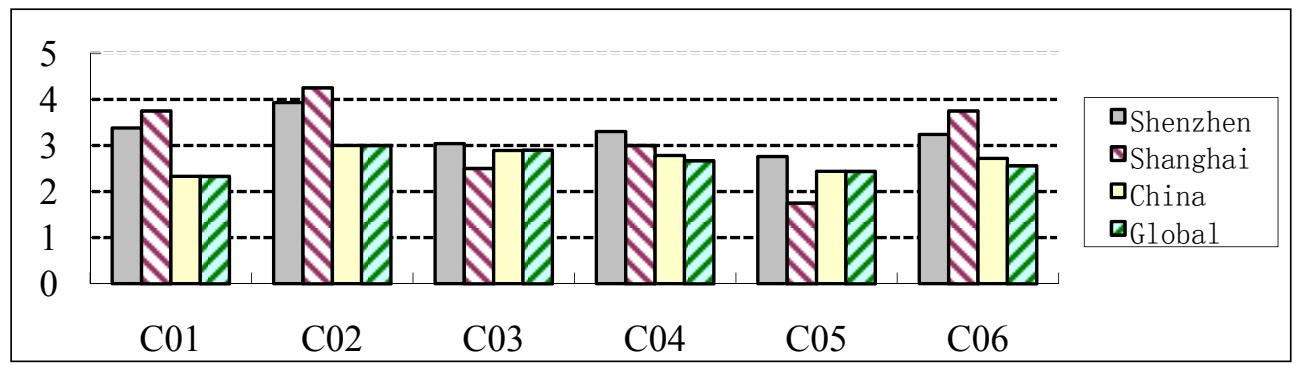

Figure 3. The Result Comparison of Expert Questionnaire (Government Programs)

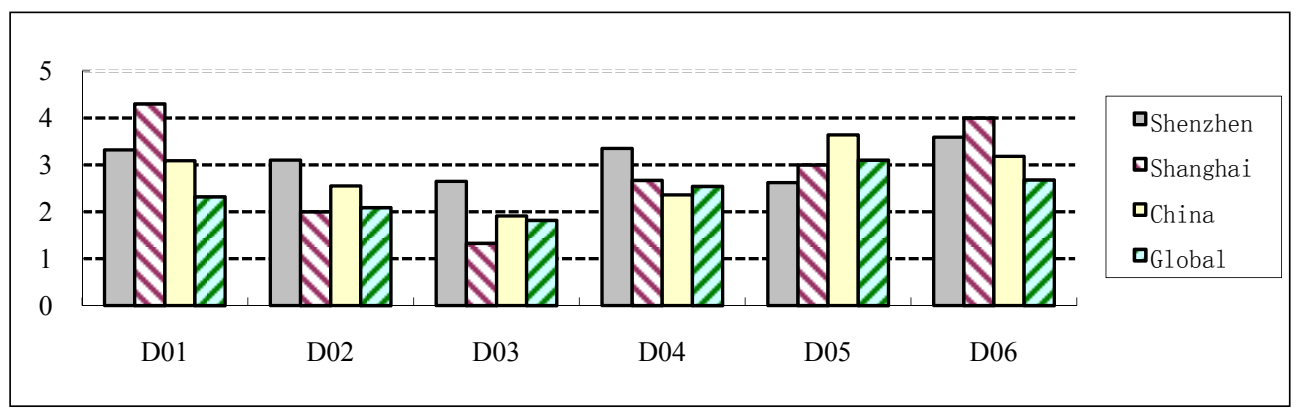

Figure 4. The Result Comparison of Expert Questionnaire (Education and Training)

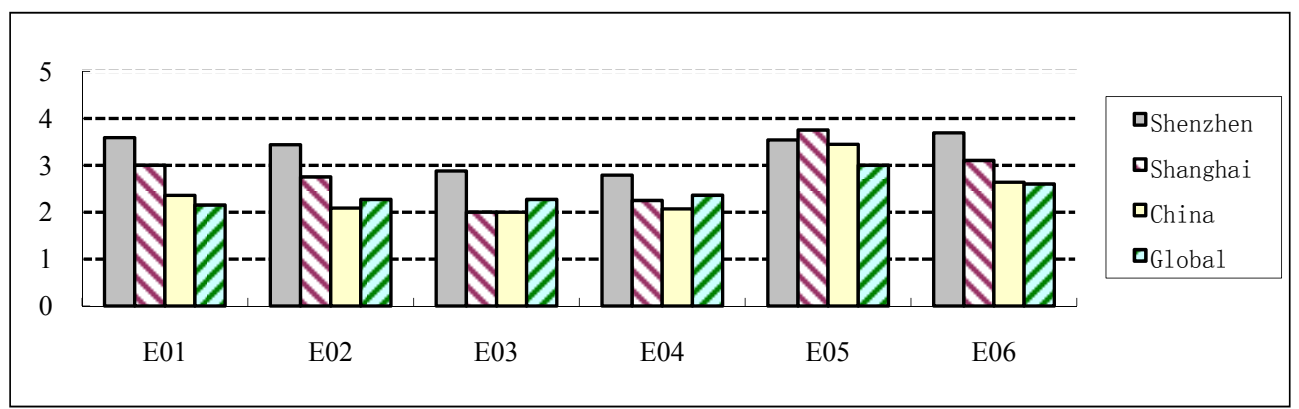

Figure 5. The Result Comparison of Expert Questionnaire (Research and Development Transfer) 


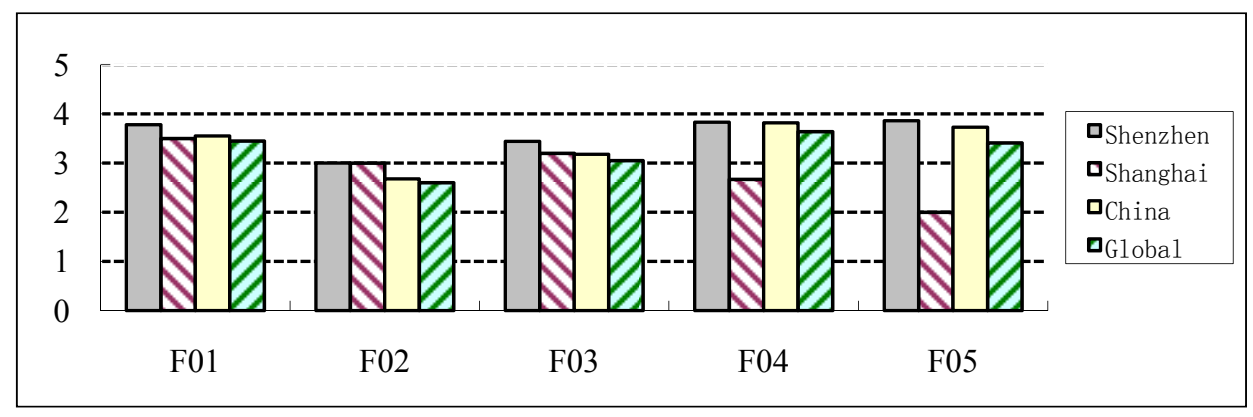

Figure 6. The Result Comparison of Expert Questionnaire (Commercial and Professional Infrastructure)

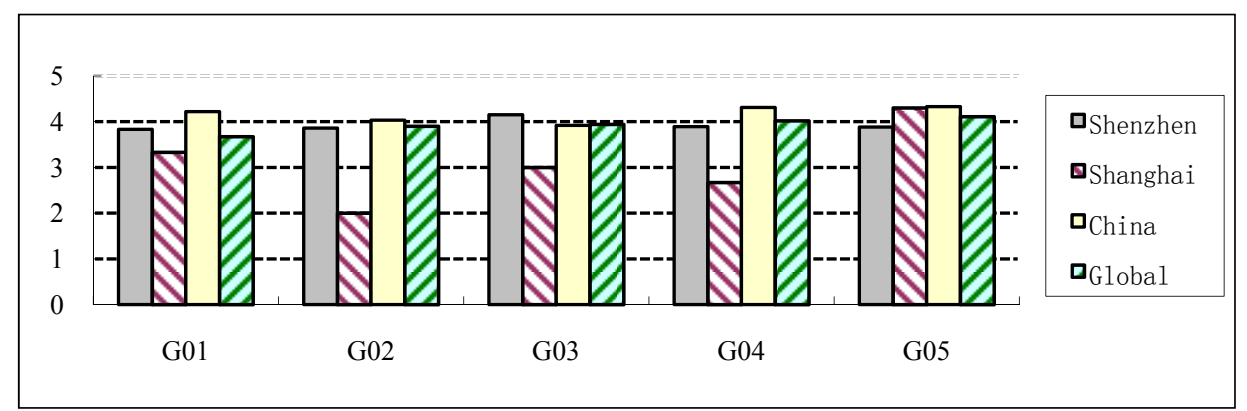

Figure 7. The Result Comparison of Expert Questionnaire (Access to Physical Infrastructure)

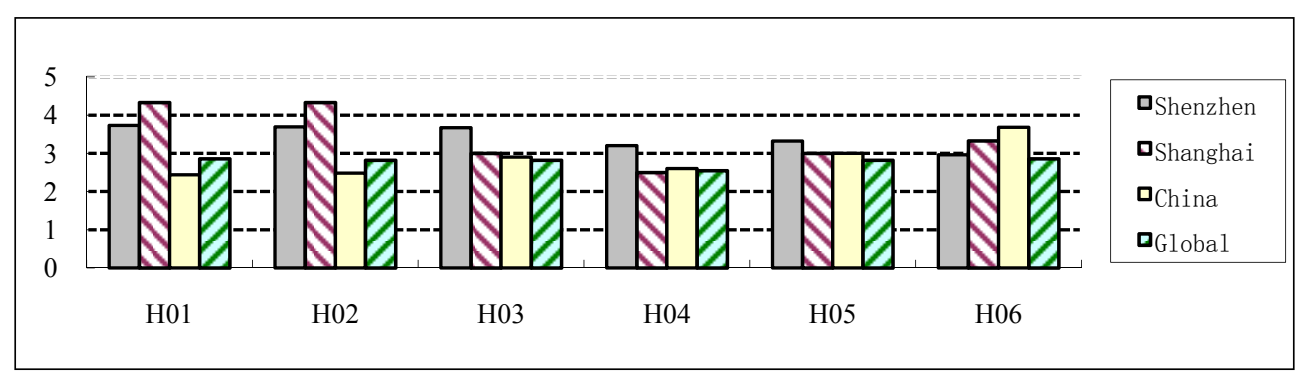

Figure 8. The Result Comparison of Expert Questionnaire (Market Openness)

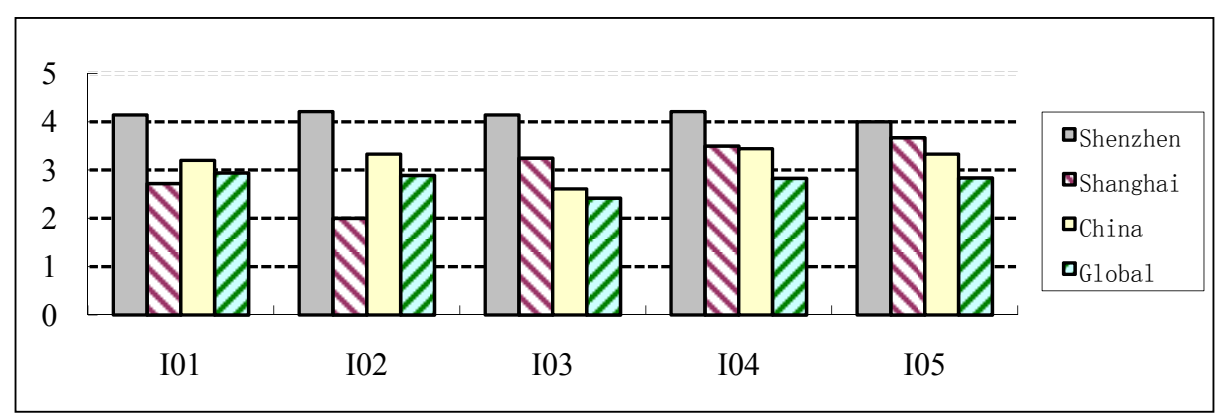

Figure 9. The Result Comparison of Expert Questionnaire (Cultural and Social Norms) 